Boise State University

ScholarWorks

Geosciences Faculty Publications and

Presentations

Department of Geosciences

10-16-2017

\title{
Acoustic and Seismic Fields of Hydraulic Jumps at Varying Froude Numbers
}

Timothy J. Ronan

University of North Carolina at Chapel Hill

Jonathan M. Lees

University of North Carolina at Chapel Hill

T. Dylan Mikesell

Boise State University

Jacob F. Anderson

Boise State University

Jeffrey B. Johnson

Boise State University

This document was originally published in Geophysical Research Letters by Wiley on behalf of the American

Geophysical Union. Copyright restrictions may apply. doi: 10.1002/2017GL074511 


\section{Geophysical Research Letters}

\section{RESEARCH LETTER \\ 10.1002/2017GL074511 \\ Acoustic and Seismic Fields of Hydraulic Jumps at Varying Froude Numbers}

Key Points:

- For detectable and coherent

seismoacoustic energies to be generated, a standing wave must exceed a threshold Fr value of approximately 1.7

- Hydrodynamic processes may partially control the spectral content of the seismic and acoustic energies

- Variations in the width and amplitude of seismoacoustic spectral peaks may be explained by horizontal variations across a hydraulic jump

Supporting Information:

- Supporting Information S1

Correspondence to:

T. J. Ronan,

ronantim06@gmail.com

\section{Citation:}

Ronan, T. J., Lees, J. M.,

Mikesell, T. D., Anderson, J. F., \& Johnson, J. B. (2017). Acoustic and seismic fields of hydraulic jumps at varying froude numbers. Geophysical Research Letters, 44. https://doi.org/10.1002/2017GL074511

Received 20 JUN 2017

Accepted 28 AUG 2017

Accepted article online 1 SEP 2017

C2017. American Geophysical Union. All Rights Reserved.

\author{
Timothy J. Ronan ${ }^{1}$ (D), Jonathan M. Lees ${ }^{1}$ (D) , T. Dylan MikeselI ${ }^{2,3}$ iD, Jacob F. Anderson ${ }^{3}$ (D), \\ and Jeffrey B. Johnson ${ }^{3}$ \\ ${ }^{1}$ Department of Geological Sciences, University of North Carolina at Chapel Hill, Chapel Hill, NC, USA, \\ ${ }^{2}$ Environmental Seismology Laboratory, Department of Geosciences, Boise State University, Boise, ID, USA, \\ ${ }^{3}$ Department of Geosciences, Boise State University, Boise, ID, USA
}

\begin{abstract}
Mechanisms that produce seismic and acoustic wavefields near rivers are poorly understood because of a lack of observations relating temporally dependent river conditions to the near-river seismoacoustic fields. This controlled study at the Harry W. Morrison Dam (HWMD) on the Boise River, Idaho, explores how temporal variation in fluvial systems affects surrounding acoustic and seismic fields. Adjusting the configuration of the HWMD changed the river bathymetry and therefore the form of the standing wave below the dam. The HWMD was adjusted to generate four distinct wave regimes that were parameterized through their dimensionless Froude numbers ( $F r)$ and observations of the ambient seismic and acoustic wavefields at the study site. To generate detectable and coherent signals, a standing wave must exceed a threshold $F r$ value of 1.7, where a nonbreaking undular jump turns into a breaking weak hydraulic jump. Hydrodynamic processes may partially control the spectral content of the seismic and acoustic energies. Furthermore, spectra related to reproducible wave conditions can be used to calibrate and verify fluvial seismic and acoustic models.
\end{abstract}

\section{Introduction}

Rivers are known to generate infrasonic and seismic energy (Burtin et al., 2008; Johnson et al., 2006; Schmandt et al., 2013). Discharge-dependent excitation of seismic and acoustic wavefields near rivers suggests that energy is transferred from hydraulic head into seismoacoustic waves. Recent work has sought to determine and describe the mechanisms that generate these fields around rivers (Burtin et al., 2008; Gimbert et al., 2014; Tsai et al., 2012; Schmandt et al., 2013). The proposed mechanisms include turbulence (Burtin et al., 2008; Hsu et al., 2014), sediment transport (Burtin et al., 2008; Hsu et al., 2011), and fluid tractions generated by fluid flow interacting with the bottom of the river (Schmandt et al., 2013). Hysteresis observed in the seismic field above $1 \mathrm{~Hz}$ led early studies to emphasize the role of sediment transport as a primary mechanism of seismic energy generation during seasonal cycles with varied discharge (Burtin et al., 2008; Hsu et al., 2011). Investigators have begun to associate distinct frequency bands within the seismic and acoustic spectra to different fluvial processes (Schmandt et al., 2013). Because hysteresis of near-river seismic signals has recently been attributed to both turbulence and bed load transport (Roth et al., 2017), correlations between band-limited seismoacoustic frequencies, hydrodynamics, and sediment transport exist and isolating single components is difficult. However, if isolated, these signals could be used to remotely monitor fluvial systems from seismic and acoustic fields.

Currently, there is a lack of evidence that robustly connects fluvial processes to the seismoacoustic fields generated near rivers, so the usefulness of these observations is limited (Tsai et al., 2012). Theoretical models of turbulence (Gimbert et al., 2014) and sediment transport (Tsai et al., 2012) have been used to link river conditions to near-river seismic observations. However, these models suffer from uncertainty due to a lack of empirically derived parameters that are used for model calibration (Gimbert et al., 2014). The Harry W. Morrison Dam (HWMD) study addresses this problem by parameterizing the discharge and bathymetry-dependent Froude number of a water wave and associating the surrounding acoustic and seismic fields to these measured wave parameters. The Boise River was between flood events during the HWMD experiment (U.S. Geological Survey (USGS), 2016); therefore, minimal change occurred in the arrangement of river's bed sediments (e.g., Roth et al., 2017). Because of this bed stability, sediment transport was negligible at the HWMD 


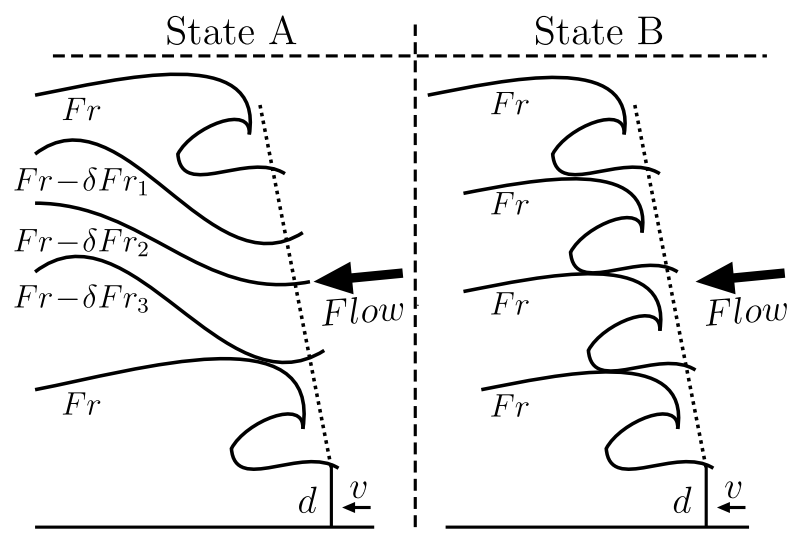

Figure 1. Examples of noncontinuous (State A, Figure 3:Wave C) and continuous (State B, Figure 3:Wave D) standing river waves. The continuous feature acts as a consistently oscillating unit on the surface of the wave, while the noncontinuous features function as multiple surficial units operating independently of one another. In the example of a noncontinuous wave (State A), $\delta F r$ values occur because of changes in the river's bathymetry and/or velocity across the wave. during the time of this study, and it is discarded as a possible source of the observed wavefields. Instead, we focus on the hydraulic jump generated by the HWMD.

The temporally dependent shape of a hydraulic jump is quantified by the dimensionless Froude number (Fr) (e.g., Te Chow, 1959):

$$
F r=\frac{v}{\sqrt{g d}},
$$

where $v$ is the velocity of the incoming fluid at the top of the jump, $d$ is the height of the water column at the lowest point in the jump, and $g$ is gravitational acceleration (Figure 1). Descriptions of different wave shapes are included in Table S1 in the supporting information. Our hypothesis is that the spectral content of seismic and acoustic energy originating from the HWMD hydraulic jump are controlled by the properties of the jump, which can be characterized by the Fr. To test this hypothesis, the Fr of the wave formed below the HWMD is systematically adjusted and compared to the energy of the surrounding seismic and acoustic wavefields.

\section{Study Site}

The HWMD is a river-wide adjustable feature at the Boise River Park located in the Boise River, Idaho, USA (Figure 2). The dam is an adjustable hydraulic jump for recreational purposes. This feature is equipped with seven flash boards raised or lowered by pneumatic air bladders. Directly downstream of two sections of flash boards are underwater plates with transformable dip angles controlled by hydraulic compressors. These plates are known as the wave shapers.

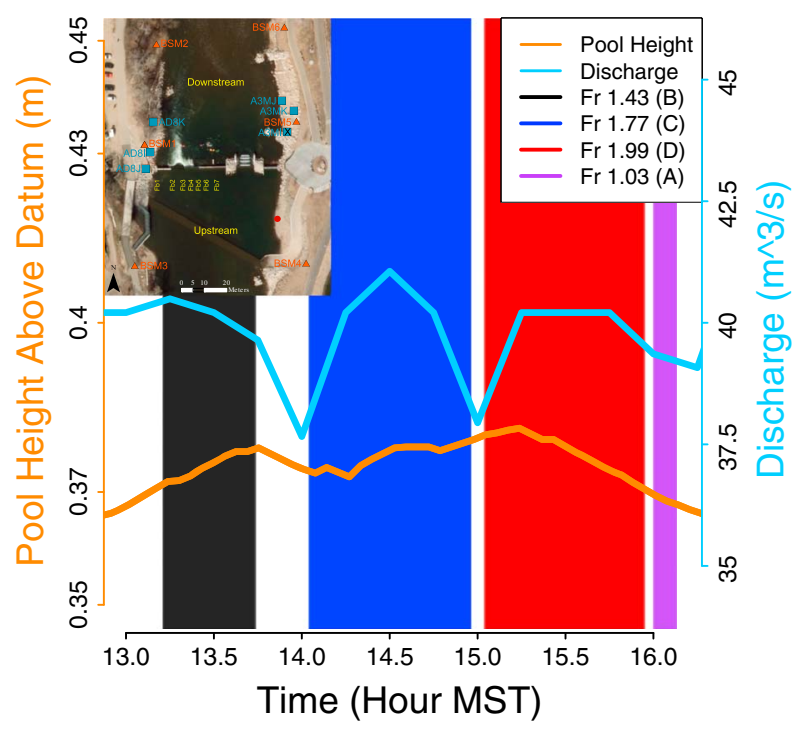

Figure 2. (top left) Map of the Harry W. Morrison dam. Triangles indicate seismometers, and squares indicate infrasound microphones during the 23 June 2016 experiment. Microphone A3M-I is marked with a black cross because of instrument failure during experimentation. Flash boards are denoted by $\mathrm{Fb}$ \#. Note that the flash boards open in the image are different than those open during the 23 June 2016 experiment. Figure panel: river discharge measured at the Glenwood Bridge USGS gauge station $4.8 \mathrm{~km}$ downstream of the HWMD and the pool height of the HWMD, which has a measurement location denoted by the red point on the map in Figure 2 (top left). Vertical rectangles indicate the time intervals of seismoacoustic observations analyzed during each Froude regime.
The shape of a standing water wave is a function of river morphology and discharge (Te Chow, 1959). Components of the HWMD can be adjusted to change the river bathymetry and, therefore, the $\mathrm{Fr}$ of a transformable downstream hydraulic jump. The adjustable parameters of the HWMD make it a river-scale flume that can form a number of turbulent regimes dependent upon river discharge. The Boise River discharge is dam-controlled approximately $25 \mathrm{~km}$ upstream. During the 23 June 2016 experiment Boise River discharge was approximately $40 \mathrm{~m}^{3} / \mathrm{s}$, which is near the historic median for this date (USGS, 2016). The flash boards and wave shapers were adjusted so that the majority of discharge was channeled through the western wave shaper. The wave generated by this wave shape is assumed to adequately characterize the temporally dependent wave conditions at the HWMD.

\subsection{River Parameters}

The experimental hydraulic jump was generated directly downstream of the HWMD. For each bathymetric profile, this jump was parameterized by measuring controllable river conditions at the jump: depth $(d)$, velocity $(v)$, and dam geometry (Figure 3 ). A technician manipulated the river bathymetry by varying the angle of seven flash boards that make up the HWMD, shaping the hydraulic jump into four distinct configurations (Figure 3). The river parameters mentioned above were collected for each wave configuration. The depth was determined using a graduated avalanche probe that vertically pierced the water surface and stopped at the river bottom. The submerged probe length was considered to be the depth of the jump. The incoming velocity at the water surface was quantified using particle-tracking velocimetry, a video 

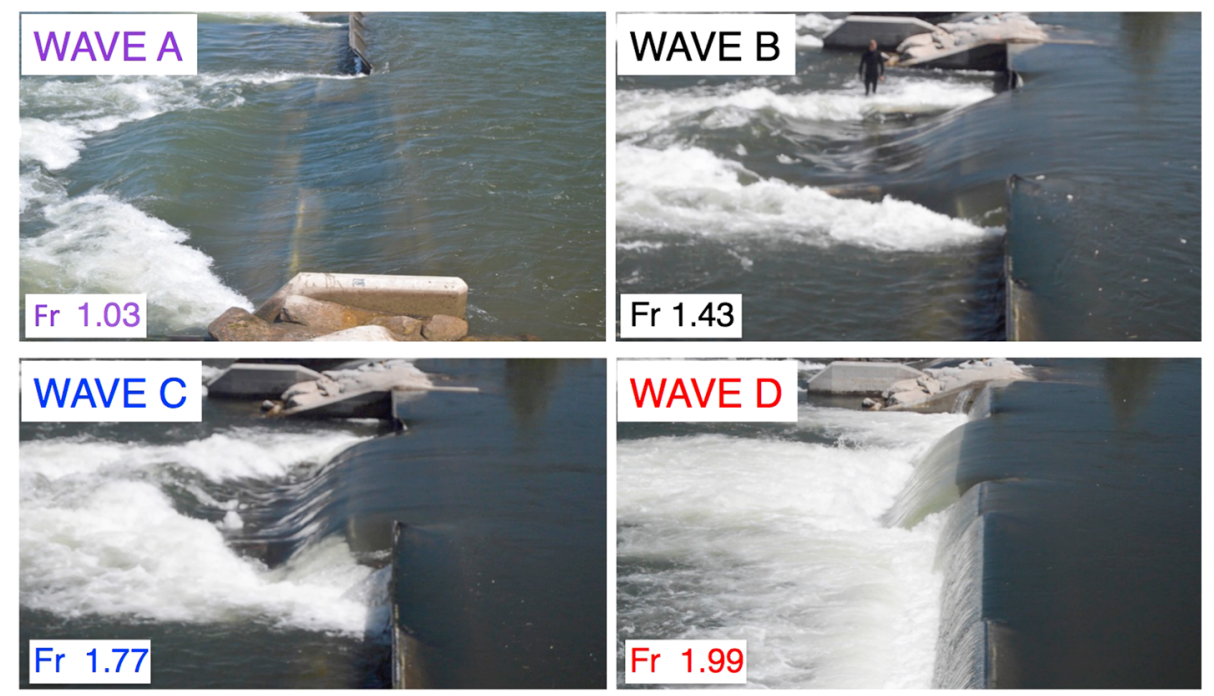

Figure 3. Images of Waves A-D; the person in the Wave B photo provides a sense of scale. Note that the photo of Wave $A$ is taken from a slightly different perspective compared to the other waves. The Froude number, and its variance, of each wave is calculated from parameter values found in supporting information Table S2.

processing technique that tracks the downstream motion of a floating object to approximate the local surface water velocity (Bradley et al., 2002).

The Froude number of each wave is calculated by inserting the collected river parameters into equation (1). Waves A-D are ordered by increasing Froude number and distinct shapes depending on the Fr value (Figure 3). Due to limited access to the hydraulic jump, estimates of river parameters used to calculate $F r$ are point measurements. In this study each wave is represented by a constant $F r$ but note that $F r$ likely changes across the wave; effects of this heterogeneity are discussed in section 6.3. The HWMD acts as an irrigation diversion dam as well a recreation site. The duration of each wave configuration varied because a certain flow had to be maintained for downstream irrigators pulling water from the HWMD pool. Most notably, Wave A had to be terminated early to minimize disruptions to downstream irrigators. Therefore, for analytical consistency, we select and analyze time windows of equal duration from each wave.

Altering river bathymetry caused changes in the upstream pool height and thus total discharge over the HWMD. Discharge measured at the Glenwood Bridge gauge station, located approximately $4.8 \mathrm{~km}$ downstream from the study site, was used to estimate river flux during the HWMD experiment. Flow conditions did not become completely steady state during experimentation with a maximum variance in discharge of approximately $2 \%$ (Figure 2). Small variations in discharge introduce error into Froude number measurements of each hydraulic jump, which may lead to less well-defined jumps and corresponding spectral peaks. In order to minimize variations introduced by small changes in river flow, temporal and spatial averaging of seismic and acoustic spectra was utilized during data processing.

\section{Data Acquisition}

A network of sensors was spatially distributed to capture heterogeneous seismic and acoustic fields (Figure 2). The seismic measurements were collected using seven nanometrics meridian digital seismometers. Data were recorded at 250 samples per second (sps). The acoustic measurements were collected using six infraBSU microphones recorded on Datacubes at 200 sps. InfraBSU sensors are flat in the band above $0.04 \mathrm{~Hz}$ and are microelectromechanical devices-based transducers similar to sensors described in Marcillo et al. (2012). Raw waveform amplitudes were transformed to physical units using instrument specific conversion factors, and all data were detrended; then, discrete time intervals of the data associated with each of the four Froude regimes were extracted.

\section{Data Analysis Methods}

Several data processing methods were applied in order to characterize the seismic and acoustic wavefields and relate them to changing properties of the jumps. First, temporally averaged acoustic spectra are calculated 


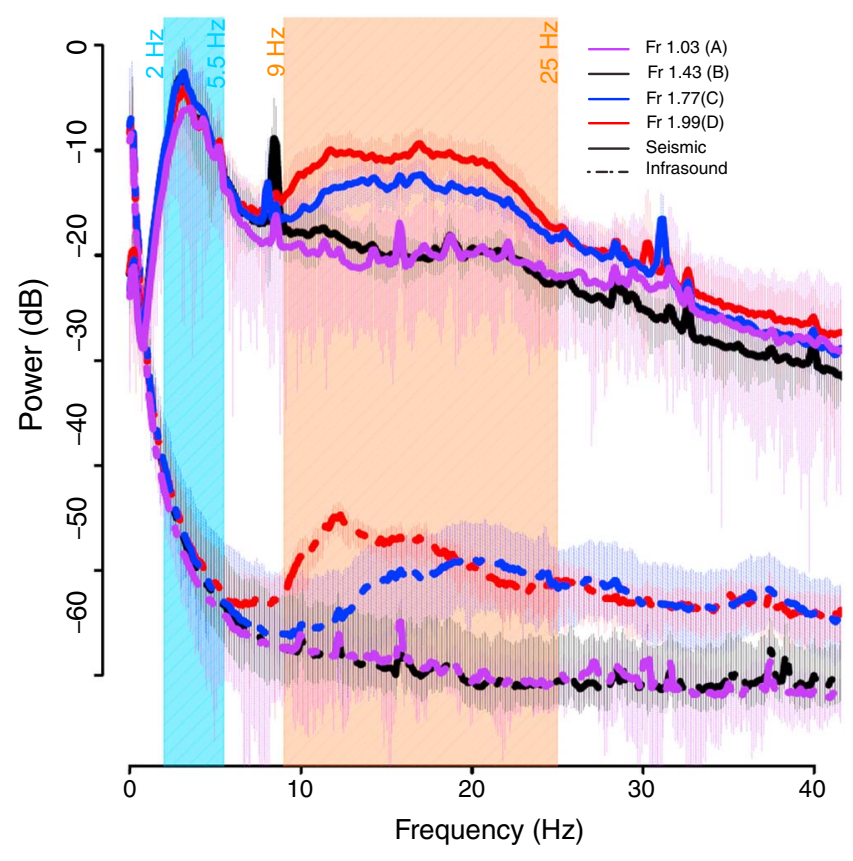

Figure 4. Network-averaged Welch power spectral density (PSD) estimates of seismic and acoustic fields during each wave shape. Both data sets are filtered between 0.1 and $100 \mathrm{~Hz}$ and are presented as decibel relative to $(\mathrm{m} / \mathrm{s})$ for seismic and pascal for acoustic energies. Thin vertical lines surrounding the spectra represent the variance at each frequency with $95 \%$ confidence intervals. Cyan $(2-5.5 \mathrm{~Hz})$ and orange $(9-25 \mathrm{~Hz})$ rectangles represent regions of interest. Seismic spectra were generated using boxcar window lengths consisting of 1,274 samples incremented by the same sample interval; acoustics spectra were generated using boxcar window lengths consisting of 1,024 samples incremented by the same sample interval. to identify spectral signatures associated with each Froude regime. Second, the spatial consistency of acoustic spectral contents was verified by calculating the averaged coherence of energy across the infrasound network. Finally, averaged seismic spectra were calculated and compared to the acoustic spectral response and Froude number of each wave.

\subsection{Power Spectral Density}

Estimates of the average power spectral density (PSD) of the seismic and acoustic fields were generated by calculating Welch averaged spectra (Welch, 1967) (following Burtin et al., 2008). Welch PSD estimates averaged spectra from 1,024 boxcar windows of approximately $5 \mathrm{~s}$ lengths incrementing by the same time interval for both acoustic and seismic data. The spectral variance was calculated at each frequency $f$ as the averaged covariance of all sets of subsequent spectra (Welch, 1967). The Welch PSD estimates and the associated variance were then spatially averaged across the instrument network. Temporally and spatially averaged PSDs provide a robust estimate of the seismic and acoustic frequency content contemporaneous with each wave shape.

\subsection{Cross-Spectral Coherence}

Cross-spectral coherence $\gamma(f)$ is a measure of similarity between spectra $s(x, f)$ and spectra $s(y, f)$ collected at positions $x$ and $y$ across frequencies $f$ (Foster \& Guinzy, 1967). Cross-spectral coherence can be interpreted as a proxy for the signal-to-noise ratio (SNR) across a network (Hayashi, 1982). Anthropogenic noise present in the urban environment around the HWMD makes quantification of SNR critical to understanding the Froude number's relationship to the seismic and acoustic fields. Thus, $\gamma(f)$ values are calculated from 0 to $40 \mathrm{~Hz}$ using boxcar windows of $900 \mathrm{~s}$ (18,000 samples) for all microphone pairs during each Froude regime:

$$
\gamma(f)=\frac{\left|s_{x y}(f)\right|}{\left[s_{x}(f) s_{y}(f)\right]^{\frac{1}{2}}}
$$

where $s_{x y}(f)$ is the cross spectrum of $s_{x}(f)$ and $s_{y}(f)$ (Hinich \& Clay, 1968). Cross-spectral coherence values are then spatially averaged, and statistics of $1 \mathrm{~Hz}$ bins is computed (Figure 5).

\section{Results}

Analysis methods described in section 4 are applied to time periods corresponding with each Froude regime (Figure 2). From these calculations, the averaged seismoacoustic spectra and spatial coherence observations are compared to the parameterized water waves. The acoustic data are first considered, and the seismic results are discussed in section 5.3. The travel paths and media through which the acoustic and seismic waves propagate may explain differences between the seismic and acoustic spectral content.

\subsection{Acoustic Spectra}

For each hydraulic jump, the PSD estimates of the acoustic wavefield across the network (Figure 4) are averaged. Wave C ( Fr 1.77) shows elevated spectral power across the 9-30 Hz frequency bands, while Wave D (Fr 1.99) displays a spectral peak between 9 and $15 \mathrm{~Hz}$ (Figures 4 and 5) compared to the PSD estimate of Wave $A$, which is considered the background reference. Bands of elevated spectral power in both Waves $C$ and $D$ coincide with frequencies of highest cross coherence (Figure 5). The PSD estimates of Waves A (Fr 1.03) and B ( Fr 1.43) do not display coherent spectral peaks; rather, they contain primarily incoherent signals with a few isolated peaks (Figures 4 and 5). The shape of the average acoustic PSD estimate associated with Waves $C$ and D suggests that the acoustic field surrounding the HWMD gains power in specific frequency bands as the Froude number increases past a threshold value (blue to red in Figure 4).

PSD estimates for all acoustic wavefields contain high-power low-frequency acoustic noise. This acoustic signal is classified as noise because it does not display cross-spectral coherence (Figure 5) and is likely 

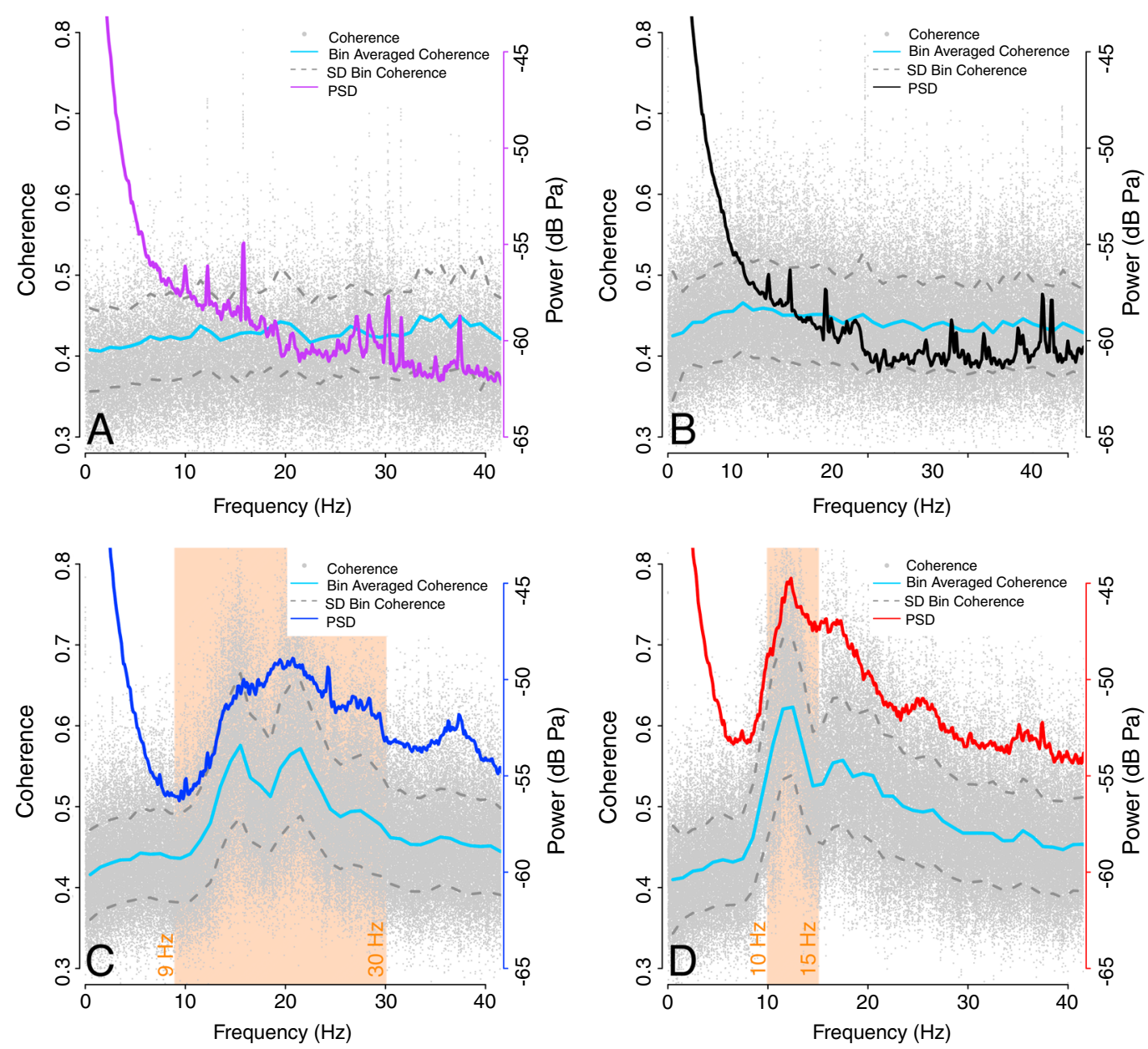

Figure 5. Network-averaged cross-spectral coherence estimates of the acoustic wavefield for each Froude regime. The corresponding network-averaged PSD is superimposed for comparison. Cross-spectral coherence results are binned into $1 \mathrm{~Hz}$ bins, and the statistics is computed; mean is shown in cyan; standard deviation is displayed by gray dashed lines. Waves $A$ and $B$ do not display elevated coherence values centered around specific frequencies, indicating a lack of coherent acoustic signal. Waves $C$ and $D$ contain distinct peaks of increased coherence. These frequency peaks are also observed in the PSD estimate. Rectangles indicate regions of interest.

explained by long-period pressure fluctuations associated with wind noise and site-specific thermal noise (e.g., Bowman \& Lees, 2015).

\subsection{Acoustic Cross-Spectral Coherence}

The cross-spectral coherence between all acoustic station pairs for each hydraulic jump are averaged (Figure 5). The spatially averaged measurements indicate strong coherence over specific frequency bands in the acoustic wavefields during Waves $C$ and $D$. Alternatively, there is very little cross-spectral coherence in any frequency band associated with Waves $A$ and $B$ (Figure 5 ). Both Waves $A$ and $B$ are defined by Froude numbers below 1.7, which is considered the threshold required to transition from a nonbreaking undular jump to a breaking weak hydraulic jump (Te Chow, 1959). The cross-spectral coherence results are binned into $1 \mathrm{~Hz}$ increments, and the bin statistics are computed. Waves A and B do not display elevated coherence values, indicating a lack of spatially similar acoustic signal; they also show a flat coherence value across all bins of around 0.45 . Alternatively, Waves $C$ and $D$ contain distinct peaks of increased coherence. A similar pattern of changing frequency peaks is observed in the seismic PSD estimates.

\subsection{Seismic}

A peak between 2 and $5.5 \mathrm{~Hz}$ is present in the seismic PSDs of each of the Froude regimes. The frequency and power of the $2-5.5 \mathrm{~Hz}$ peak do not vary significantly with $F r$, suggesting that water surface dynamics are not the mechanism that generates this lower frequency seismic band. In the $9-25 \mathrm{~Hz}$ band, seismic PSDs of 
Waves $C$ and $D$ display elevated power compared to Waves $A$ and B. The increased power in the 9 to $25 \mathrm{~Hz}$ seismic band of Waves $C$ and $D$ suggest a correlation between the Froude number of hydraulic jumps and frequency bands of the seismic field that surrounds the wave (Figure 4). Disparities in spectral content between the $9-25 \mathrm{~Hz}$ seismic and acoustic frequency bands may be explained by differences in attenuation, especially at higher frequencies where wavelengths are significantly different in air compared to the solid Earth. Moreover, seismic energy experiences greater attenuation than acoustic energy produced by fluvial processes (e.g., Huang et al., 2008).

Cross-spectral coherence tests conducted across the seismic array do not display definitive coherent peaks. The discrepancy in coherency between the seismic and acoustic data sets may arise from differences in wave propagation through their respective media. Compared to the atmosphere, the Earth is a more complex propagation medium: scattering from material heterogeneities and varying wave speeds may make the coherence of seismic recordings variable.

\section{Discussion}

The shape of a hydraulic jump affects the spectral content of the surrounding seismoacoustic wavefields. Regions of elevated seismoacoustic spectra suggest that a jump's Froude regime is above a threshold value of approximately 1.7, where undular jumps transform into weak hydraulic jumps (Te Chow, 1959). Above this threshold, jumps oversteepen and begin to collapse on themselves in oscillatory patterns (Mossa, 1999) that likely control the frequency content of the seismic and acoustic energies. The amplitude and peakedness of acoustic spectral maxima are likely influenced by the uniformity of oscillation across a hydraulic jump.

\subsection{Threshold Conditions}

A water wave must exceed a threshold Froude condition before it excites coherent energy in both the acoustic and seismic fields. We make this interpretation because acoustic signals associated with Waves $A$ and $B$ do not contain coherent frequency bands, while Waves $C$ and $D$ generate coherent frequency bands of elevated power in comparison to Waves A and B (Figure 5). The change in wave shape that occurs at transitional Froude numbers (Te Chow, 1959) may explain disparities in the coherence of the acoustic field for each jump. We captured the transitional Froude number of 1.7, where a nonbreaking undular jump turns into a breaking weak hydraulic jump. This transition, from an undular jump to a weak hydraulic jump, is expressed in the surrounding acoustic field by emerging coherent spectral peaks (Figures 4 and 5). Although seismic cross-spectral coherence results do not display coherent frequency bands, the $9-25 \mathrm{~Hz}$ seismic frequency band shows increasing power correlated to the Froude number, similar to that observed in the acoustic wavefield. This suggest that energy transfer into the seismic field may also be affected by threshold Froude regimes. As the water wave transitions above the threshold Froude number of 1.7, it begins to collapse on itself, transferring kinetic energy into the seismic and acoustic fields in accordance with the periodicity of the breaking wave.

We suggest that breaking river waves are a mechanism of seismoacoustic generation. This mechanism is consistent with previous interpretations including the explanation of the $2-15 \mathrm{~Hz}$ band surrounding the Hance Rapid on the Colorado River, Arizona, as interactions at the "fluid air interface" (Schmandt et al., 2013) and studies that attribute infrasound generation to breaking ocean waves (e.g., Aucan et al., 2006). A stationary breaking wave can be idealized as an oscillating piston that couples hydraulic head into both atmospheric compressional waves and terrestrial elastic waves. The model described above is similar to theories on how long-period standing ocean waves generate microbarometric and microseismic energy during each pulse of a single source ocean wave (Ardhuin \& Herbers, 2013). Although standing ocean waves are generated from wave-wave interactions (Ardhuin \& Herbers, 2013) while stationary river waves are formed by the interaction of a single hydraulic jump, it is conceivable that these standing waves couple energy into the atmosphere and solid Earth through similar mechanisms. Because breaking hydraulic jumps generate seismoacoustic waves, the temporally dependent activity of a river wave should be observable within the acoustic and seismic signals.

\subsection{Frequency Content}

Frequency content of seismoacoustic energy surrounding a hydraulic jump may be partially controlled by hydrodynamics. Observed spectral peaks in the near-river wavefields are likely associated with cyclical oscillations of a water wave. We propose that one period of a seismoacoustic wave is generated during each cycle of its source water wave. Therefore, a water wave's frequency of oscillation will be present in the seismic and acoustic wavefields. Wave D's increased Froude number is associated with an acoustic spectral peak 
centered around lower frequencies than those observed in the acoustic field surrounding Wave $C$ (Figure 4). Previous empirical studies have concluded that water wave-surface oscillations are a function of the Froude number (Mossa, 1999), where there is an inverse correlation between the Froude number and the frequency of wave-surface oscillations (Chachereau \& Chanson, 2011). Discharge-dependent Froude numbers may partially control the frequency content of the seismoacoustic wavefields near hydraulic jumps. This mechanism partially explains the drift in infrasonic peak frequency observed throughout the flood cycle of the Hance Rapid acoustic data set (Gimbert et al., 2014; Schmandt et al., 2013). Since the Froude number is a function of discharge (Te Chow, 1959), both the frequency content of the hydraulic jump's surface oscillations and the seismoacoustic fields should shift throughout a flood cycle.

\subsection{Wave Continuity}

Consistency of shape across a water wave may partially explain the variations in the width and amplitude of spectral peaks within the seismoacoustic fields surrounding Waves $C$ and D (Figure 4). We propose that the continuity of wave shape (Figure 1), or the horizontal variation of the Froude number, influences characteristics of the PSD. Visual inspection of Wave D (Figure 3) displays a semicontinuous wave of quasi-uniform oscillation across the majority of the feature in comparison to all other Froude regimes. Uniform oscillation across a wave should generate a narrower frequency peak with minimal variance because the wave contains fewer distinct surfaces of oscillation. Spectral amplitude is also affected by this model. We suspect liquid mass flux per oscillation increases when a wave functions as a singular unit, and increased mass flux generates greater forces that are likely converted into increased PSD amplitudes following the Gimbert et al. (2014) model. Seismic and acoustic spectral observations of Waves $C$ and $D$ display patterns that are consistent with the wave continuity phenomenon (Figure 4). Wave D displays increased power in the $9-30 \mathrm{~Hz}$ seismoacoustic spectral band and a narrower acoustic frequency peak with low variance in comparison to Wave C (Figure 4). Furthermore, continuity of oscillation across a wave should generate seismoacoustic energy that is spatially similar. This is observed in Wave D's acoustic cross-spectral coherence result, which displays band-limited energy that is spatially coherent and follows the shape of the average acoustic PSD estimate (Figure 5).

\section{Conclusion}

This study conducted a flume-like experiment that explores the correlation between the shape of hydraulic jumps and their surrounding seismoacoustic fields. The frequency content of spatially averaged seismoacoustic spectra adjusted as the Froude number of a transformable hydraulic jump was systematically changed. A threshold Froude number, which must be passed in order to generate coherent wavefields, explains the appearance and disappearance of frequency peaks in both the seismic and acoustic fields. Changing power spectral density and cross-spectral coherence estimates suggest that near-river acoustic and seismic wavefields are influenced by temporally dependent hydrodynamic patterns. Controlled, full-scale fluvial seismoacoustic studies provide insight into the relationship between hydrodynamics processes and their seismoacoustic energies, which can be implemented in natural settings to better understand sediment transport, turbulence, and river flood processes.

Acknowledgments

T. J. Ronan thanks National Science Foundation (NSF)[10.13039/100000001] (CDI-1125185) and the Martin Fund, University of North Carolina at Chapel Hill for financial support. T. D. Mikesell thanks Boise State University for financial support. All authors thank the City of Boise Parks and Recreation, Paul Primus, Paul Schonfielder, Paul Collins, Larry Otheim, Jordan Johnson, Hugo Ortiz, and Will Wicherski for help with data collection during the HWMD seismoacoustic experiments. The data used are listed in Boise State University Scholar Works data repository at DOI:https://doi.org/10.18122/B2K30X.

\section{References}

Ardhuin, F., \& Herbers, T. (2013). Noise generation in the solid Earth, oceans and atmosphere, from nonlinear interacting surface waves in finite depth. Journal of Fluid Mechanics, 716, 316-348. https://doi.org/10.1017/jfm. 2012.548

Aucan, J., Fee, D., \& Garces, M. (2006). Infrasonic estimation of surf period. Geophysical Research Letters, 33, L05612. https://doi.org/10.1029/2005GL025086

Bowman, D. C., \& Lees, J. M. (2015). Infrasound in the middle stratosphere measured with a free-flying acoustic array. Geophysical Research Letters, 42, 10,010-10,017. https://doi.org/10.1002/2015GL066570

Bradley, A. A., Kruger, A., Meselhe, E. A., \& Muste, M. V. I. (2002). Flow measurement in streams using video imagery. Water Resources Research, 38(12), 1315. https://doi.org/10.1029/2002WR001317

Burtin, A., Bollinger, L., Vergne, J., Cattin, R., \& Nabelek, J. L. (2008). Spectral analysis of seismic noise induced by rivers: A new tool to monitor spatiotemporal changes in stream hydrodynamics. Journal of Geophysical Research: Solid Earth, 113, B05301. https://doi.org/ 10.1029/2007JB005034

Chachereau, Y., \& Chanson, H. (2011). Free-surface fluctuations and turbulence in hydraulic jumps. Experimental Thermal and Fluid Science, 35(6), 896-909. https://doi.org/10.1016/j.expthermflusci.2011.01.009

Foster, M. R., \& Guinzy, N. J. (1967). The coefficient of coherence; Its estimation and use in geophysical data processing. Geophysics, 32(4), 602-616. https://doi.org/10.1190/1.1439878

Gimbert, F., Tsai, V. C., \& Lamb, M. P. (2014). A physical model for seismic noise generation by turbulent flow in rivers. Journal of Geophysical Research: Earth Surface, 119(10), 2209-2238. https://doi.org/10.1002/2014JF003201

Hayashi, Y. (1982). Space-time spectral analysis and its applications to atmospheric waves. Journal of the Meteorological Society of Japan Series II, 60(1), 156-171. 
Hinich, M. J., \& Clay, C. S. (1968). The application of the discrete Fourier transform in the estimation of power spectra, coherence, and bispectra of geophysical data. Reviews of Geophysics, 6(3), 347-363. https://doi.org/10.1029/RG006i003p00347

Hsu, L., Finnegan, N. J., \& Brodsky, E. E. (2011). A seismic signature of river bedload transport during storm events. Geophysical Research Letters, 38, L13407. https://doi.org/10.1029/2011GL047759

Huang, C.-J., Yeh, C.-H., Chen, C.-Y., \& Chang, S.-T. (2008). Ground vibrations and airborne sounds generated by motion of rock in a river bed. Natural Hazards and Earth System Sciences, 8(5), 1139-1147. https://doi.org/10.5194/nhess-8-1139-2008

Johnson, J. B., Lees, J. M., \& Yepes, H. (2006). Volcanic eruptions, lightning, and a waterfall: Differentiating the menagerie of infrasound in the Ecuadorian jungle. Geophysical Research Letters, 33, L06308. https://doi.org/10.1029/2005GL025515

Marcillo, O., Johnson, J. B., \& Hart, D. (2012). Implementation, characterization, and evaluation of an inexpensive low-power low-noise infrasound sensor based on a micromachined differential pressure transducer and a mechanical filter. Journal of Atmospheric and Oceanic Technology, 29(9), 1275-1284. https://doi.org/10.1175/JTECH-D-11-00101.1

Mossa, M. (1999). On the oscillating characteristics of hydraulic jumps. Journal of Hydraulic Research, 37(4), 541-558. https://doi.org/10.1080/00221686.1999.9628267

Roth, D. L., Finnegan, N. J., Brodsky, E. E., Rickenmann, D., Turowski, J. M., Badoux, A., \& Gimbert, F. (2017). Bed load transport and boundary roughness changes as competing causes of hysteresis in the relationship between river discharge and seismic amplitude recorded near a steep mountain stream. Journal of Geophysical Research: Earth Surface, 122(5), 1182-1200. https://doi.org/10.1002/2016JF004062

Schmandt, B., Aster, R. C., Scherler, D., Tsai, V. C., \& Karlstrom, K. (2013). Multiple fluvial processes detected by riverside seismic and infrasound monitoring of a controlled flood in the Grand Canyon. Geophysical Research Letters, 40(18), 4858-4863. https://doi.org/10.1002/grl.50953

Te Chow, V. (1959). Open-channel hydraulics. McGraw-Hill civil engineering series, McGraw-Hill.

Tsai, V. C., Minchew, B., Lamb, M. P., \& Ampuero, J.-P. (2012). A physical model for seismic noise generation from sediment transport in rivers. Geophysical Research Letters, 39, L02404. https://doi.org/10.1029/2011GL050255

U.S. Geological Survey (USGS) (2016). National water information system data available on the World Wide Web, data table.

Welch, P. (1967). The use of fast Fourier transform for the estimation of power spectra: A method based on time averaging over short, modified periodograms. IEEE Transactions on Audio and Electroacoustics, 15(2), 70-73. https://doi.org/10.1109/TAU.1967.1161901 